\title{
On Which Side of the Breast is Arakawa's Reaction More Frequently Negative in the Same Lactating Woman? (A Preliminary Note).
}

ro3rd Report of the Peroxidase Reaction.

By

Kyohachi Yoshino.

(芳 野京八)

(From the Department of Pediatrics, Faculty of Medicine, Tohoku Imperial University, Sendai. Director: Prof. A. Sato.)

Is Arakawa's reaction of human milk in one and the same woman more frequently negative on the right breast or on the left? The present paper is only a preliminary note, because, though the materials* used here were about 1000 in number, there were only a few cases suitable for the purpose.

Arakawa's reaction is usually more or less similar in intensity on both sides of the breast. There are, however, exceptional cases in which milk from one breast is very different from that from the other, -in which milk from one is completely or almost completely negative to Arakawa's reaction, while milk from the other breast is strongly or normally positive or, if it be one of intermediate reactions, of some intensity (Cf. Table).

From the fact that the negative side milk is mostly more like Arakawa-negative milk as regards the amounts of chemical ingredients, ${ }^{12) 3)}$ we can reasonably assume that such a milk-milk from a different side with very different reaction-will be from a lactating body already in a state of $\mathrm{B}_{1}$-avitaminosis. Now if such a milk is from a $\mathrm{B}_{1}$ - avitaminotic body, then why is it that a more or less "good"

* Besides my own, those examined by Ishii,I) by Kurosawa $a^{2}$ and Sugih a ra (Tohoku J. Exp. Med., 1938, 33, 558.) were used.

1) M. Is h i i, Tohoku J. Exp. Med., 1937, 31, 580.

2) T. Kurosawa. Tohoku J. Exp. Med., 1937, 31, 106.

3) Ky. Y os hin o, Tohokn J. Exp. Med., 1937, 31, 287. 
TABle.

24 cases with very different A rakawa's reaction on different sides of breast.

\begin{tabular}{|c|c|c|}
\hline \multirow{2}{*}{$\begin{array}{c}\text { No. of } \\
\text { ex- } \\
\text { peri- } \\
\text { ment }\end{array}$} & \multicolumn{2}{|c|}{ Arakawa's reaction } \\
\hline & $\begin{array}{l}\text { Right } \\
0^{\prime} 1^{\prime} 2^{\prime} 3^{\prime} 4^{\prime} 5^{\prime}\end{array}$ & $\begin{array}{c}\text { Left } \\
0^{\prime} 1^{\prime} 2^{\prime} 3^{\prime} 4^{\prime} 5^{\prime}\end{array}$ \\
\hline 1 & $-H$ H H H H & ---- \pm \\
\hline 2 & $-H H+H$ & --- \pm+ \\
\hline 3 & $---\cdots$ & $\pm H+H \cdot H \cdot H$ \\
\hline 4 & ---- \pm \pm & $+H H H H$ \\
\hline 5 & $\pm H+H H+H$ & $---\cdots$ \\
\hline 6 & ----- & $\pm+\# \# \# H$ \\
\hline 7 & $\pm \#$ H\#册 H & --- \pm \pm \pm \\
\hline 8 & 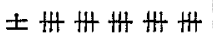 & ----- \\
\hline 9 & $----\cdots$ & $-H H H+H$ \\
\hline 10 & ----- & $+H+H$ H H \\
\hline 11 & $\pm+H$ H H H & --- \pm \pm \pm \\
\hline 12 & $\pm H \# \# \#$ & $-ー \pm \pm \pm \pm$ \\
\hline
\end{tabular}

\begin{tabular}{|c|c|c|}
\hline \multirow{2}{*}{$\begin{array}{c}\text { No. of } \\
\text { ex- } \\
\text { peri- } \\
\text { ment }\end{array}$} & \multicolumn{2}{|c|}{ Arakawa's reaction } \\
\hline & 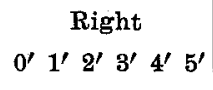 & 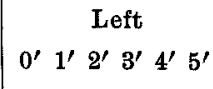 \\
\hline 13 & $-ー \pm \pm \pm \pm$ & \pm+ H H H W \\
\hline 14 & ----- & $\pm \# \# \#$ \#\# \\
\hline 15 & $\pm H H H H+H$ & ---- \pm \pm \\
\hline 16 & $\pm H+H H+H$ & -- \pm \pm \pm \pm \\
\hline 17 & t $\mathrm{HH}+\mathrm{H}+\mathrm{H} H \mathrm{Ht}$ & -- \pm \pm \pm \pm \\
\hline 18 & $-\cdots--\cdots$ & $-H H H+H$ \\
\hline 19 & -- \pm \pm++ & -+ H H H H \\
\hline 20 & $\pm+H$ \#\# H & -- \pm \pm++ \\
\hline 21 & ------ & $-+H$ H H H \\
\hline 22 & ---- \pm & $-++\#$ H H \\
\hline 23 & $-+\mathrm{H} H \mathrm{H} H$ & ------ \\
\hline 24 & 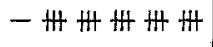 & ----- \\
\hline
\end{tabular}

milk and a "bad" milk should be secreted from one and the same body, as if half the body were healthy and the other half $\mathrm{B}_{1}$-avitaminotic?

This will be explained if it is borne in mind that milk secretion is not a simple filtration of blood, but a secretion under the control of nerves. It will be easily conceived that intercostal nerves are affected differently as to the severity or the time of injury arising from avitaminosis $B_{1}$. This will explain the slight difference of A rakaw a's reaction in many cases and the exceptionally remarkable difference (as is shown in the accompanying table) in exceptional cases.

Based on his result of the existence of only slightly affected and hyperimpregnated ${ }^{* *}$ ax cylinders in gravely affected nerves, $\mathrm{Ko}$ y a m a, ${ }^{4)}$ of the Oto-Rhino-Laryngological Department of this Faculty, suggested already the possibility of the difference of $\mathrm{B}_{1}$-avitaminotic affections of nerves on different sides of the breast.

Then it is a well known fact that hoarseness is one of frequent symptoms of infantile beriberi. Now, this symptom is, according to

** As to silber impregnation.

4) Y. K о у a m a, Tohoku Igaku Zassi, 1936, 19, 389. 
Nakamura, ${ }^{\text {5) }}$ Yanagisa $\mathrm{w}^{6}$ and $\mathrm{Kubo}$, ${ }^{7}$ due much more frequently to the paralysis of the left recurrent nerve than of the right. Koyama saw this difference also in his animal experiment. And he also attributed the cause to the severer affection of the left recurrent nerve to its peculiar anatomical position, as opposed to that of the right nerve. I shall not enter into details concerning this opinion of his.

As above stated, some lactating women secret milk of very different Arakawa's reaction from their two sides of the breast. Intercostal nerves (including vegetative nerves) may well be almost symmetrical on both sides, at least as far as nerves of mammary glands are concerned. Now, it was interesting to me to investigate on which side breast Arakawa's reaction is more frequently negative in these lactating women with very different A rakawa's reaction on different breast, because, if the result was such as will show a prevalence of negative Arakawa's reaction on the left breast, then the cause of the more frequent affection of the left recurrent nerve might have a different explanation.

As stated above, the materials used in the present paper were about 1000 in number. But $I$ was able to collect only 24 cases with remarkable difference of A rakawa's reaction on different breasts. As already explained, the 24 cases shown in the accompanying table were those mothers with either normal reaction or a rather strong reaction among intermediate reactions on one breast, and with completely or almost completely negative reaction on the other. Among. these 24 mothers, 11 cases were negative on the right breast and in the remaining 13 cases the left side milk was negative. The number was small in all, and it is more proper to conclude that in those mothers with very different Arakawa's reaction on different sides of the breast, half the cases were negative on one side and the balance on the other, rather than that a larger number of the cases were negative on the left. In a further 156 cases with a moderate difference of the reaction, just half the cases ( 78 cases) were more strongly negative*** on the left and the other half on the right.

The above described result will show that milk secreting nerves may be differently affected according to the different side of the breast in the case of avitaminosis $B_{1}$, but it seems to me that there is no

5) Y. Nak a mu ra, Dainippon Zibiinkokakai Kaiho, 1915, 21, 1153.

6) T. Yanagis a wa, Dainippon Zibiinkokakai Kaiho, 1931, 37, 543.

7) E. K u bo, Tokyo Izishinshi, 1921, No. 2209, 66.

* Though the expression may not be appropriate. 
tendency of the prevalence of the right or left side affection. The right side will be equally frequently affected as the left, though the preponderance may of course individually be different.

The cases may be still too small in number to be conclusive; the present paper is a preliminary report. But the above conclusion is interesting to me, if (probably) symmetrical nerves of mammary glands and asymmetrical recurrent nerves are taken into consideration.

\section{Summary.}

In 24 cases of lactating women with very different Arakawa's reaction on different sides of the breast, there is no prevalence of negative reaction on the right or left side. 